J. Lake Sci. (湖泊科学), $2007, \mathbf{1 9}(4): 407-412$

http:// www. jlakes. org. E-mail: jlakes@ niglas. ac. cn

(c) 2007 by Journal of Lake Sciences

\title{
近百年来湖北太白湖沉积通量变化与流域降水量和人类活动的关系
}

\author{
刘恩峰 ${ }^{1}$, 羊向东 ${ }^{1}$, 沈 吉 $^{1}$, 董旭辉 ${ }^{1,2}$, 王苏民 ${ }^{1}$, 夏威岚 ${ }^{1}$ \\ ( 1 : 中国科学院南京地理与湖泊研究所,南京 210008) \\ (2: 中国科学院研究生院, 北京 100039 )
}

摘 要: 湖泊沉积通量蕴含了流域降水量及人类活动的丰富信息. 依据太白湖沉积岩芯 ${ }^{210} \mathrm{~Pb}$ 测定结果及 $\mathrm{CRS}$ 模式, 建立 了近百年来的沉积年代序列, 对比分析了不同时期沉积通量变化与流域降水量及人类活动的关系. 1900-1920、1928、 $1937-1942 、 1953-1954$ 年沉积通量较高的四个时段,分别对应于夏季降水较多的 $1900-1920 、 1931 、 1938-1939 、 1954$ 年,沉积通量增加主要与夏季降水量偏多,被带入湖泊的泥沙量增加有关. $1958-1963$ 年,太白湖流域上游兴建三座水 库,对洪水及人湖泥沙起到了调蓄作用, 自此之后, 太白湖的平均沉积通量减小,降水量已不再是影响沉积通量的主导因 素; $1958-1970$ 年沉积通量较高,主要是太白湖围垦导致的人湖泥沙量的增加及湖泊面积减小所致; $1983-1993$ 年沉积 通量的增加则反映了农业生产方式由集体转为个体生产模式后, 耕作业的快速发展所导致的水土流失的加重. 研究结果 证明,采用 ${ }^{210} \mathrm{~Pb}$ 强度及 CRS 模式所建立的太白湖近百年来的沉积年代标尺精度较高 (误差小于 4 年),太白湖沉积环境 稳定,可采用其沉积指标进行流域及湖泊环境演化重建.

关键词: 沉积通量;降水量; 人类活动;太白湖

\section{Sedimentary flux of Lake Taibai, Hubei Province and correlations with precipitation and human activities in its catchment during the last century}

\author{
LIU Enfeng ${ }^{1}$, YANG Xiangdong ${ }^{1}$, SHEN Ji ${ }^{1}$, DONG Xuhui ${ }^{1,2}$, WANG $\operatorname{Sumin}^{1} \&$ XIA Weilan ${ }^{1}$ \\ (1: Nanjing Institute of Geography \& Limnology, Chinese Academy of Sciences, Nanjing 210008, P. R. China) \\ (2: Graduate School of the Chinese Academy of Sciences, Beijing 100039, P. R. China)
}

\begin{abstract}
Time-depth correlation of the sediment core from Lake Taibai, Hubei Province was established based on the ${ }^{210} \mathrm{~Pb}$ intensity and CRS model. The sedimentary flux variation and its correlations with the summer precipitation and human activities during the last century in Lake Taibai catchment were discussed. There were six periods with high sedimentary flux. The former four periods, $1900-1920,1928,1937-1942$ and $1953-1954$ AD, were correspondent with the four phases with a higher precipitation in summer, which were $1900-1920,1931,1938$ 1939 and 1954 AD. The high sedimentary flux was resulted from more material input by stronger runoff. After three reservoirs were built in the upstream region of Lake Taibai inflow rivers in 1958 - 1963 AD, there was a lower average sedimentary flux for Lake Taibai due to the regulation of the reservoirs to the flood and silts, and the controlling function of precipitation on sedimentary flux became weakened. The high sedimentary flux during $1958-1970$ AD was mainly related to the land reclamation around the Lake, resulting lake area decreased. The high sedimentary flux during 1983 - 1993 AD was induced by the soil erosion with the rapid development of cultivation after the change of agricultural production patterns. By the contrastive analysis of sedimentary flux with precipitation and human activities, the accuracy of the timescale of Lake Taibai sediment can be reliable, which also indicated the enough stable sedimentary environment. Thus, the sedimentary proxies can be used to reconstruct the environment evolution process in Lake Taibai catchment.
\end{abstract}

Keywords: Sedimentary flux, precipitation, human activities; Lake Taibai 
湖泊作为流域物质迁移的归宿地,其沉积物 “记录”了流域人类活动、气候变化的丰富信息,通过湖泊 沉积环境指标分析可反演湖泊生态类型演化、流域火灾、森林砍伐、农业规模变化、洪水等事件或过程 等 ${ }^{[1-5]}$. 长江中下游平原湖区是我国乃至世界上典型的浅水湖群区, 湖泊面积约 $14073 \mathrm{~km}^{2}$, 多数湖泊平均 水深只有 $2 \mathrm{~m}$ 左右 ${ }^{[6]}$, 湖泊沉积物易受风浪及人为活动的二次扰动; 大多数湖泊与长江相通, 容易受到长江 水顶托或倒灌的影响,使湖泊沉积速率加快, 甚至使沉积物组成改变 ${ }^{[7]}$; 长江中下游地区降水量年际变化 较大,而且人类活动 (水系改造、湖泊围垦、农业耕作等) 对流域及湖泊沉积环境影响明显,易导致人湖泥沙 量 (湖泊沉积通量) 的改变 ${ }^{[8,9]}$. 因此, 湖泊沉积是否连续, 沉积环境稳定性如何, 直接影响到沉积物定年的 精度, 这也成为采用湖泊沉积指标对长江中下游地区湖泊及流域环境演化重建研究的瓶颈. 湖泊沉积通量 是判断沉积物来源变化最直接的指标之一, 通过湖泊沉积通量与流域降水量及人类活动阶段性变化的对比 分析,能够判识湖泊沉积环境演化过程及其稳定性 ${ }^{[8,10,11]}$.

本文通过对长江中游太白湖沉积岩芯 ${ }^{210} \mathrm{~Pb}$ 强度的测定, 采用 CRS 模式建立了沉积岩芯的年代 - 深度 关系,在此基础上通过沉积通量变化及其与流域降水量 (洪涝)、湖泊围旺、水库修建、耕作业变化等人类活 动阶段性特征的分析, 阐明了不同时期沉积通量变化的主导因素; 对近百年来太白湖沉积环境的稳定性及 所建立的沉积年代序列的精确性进行了验证.

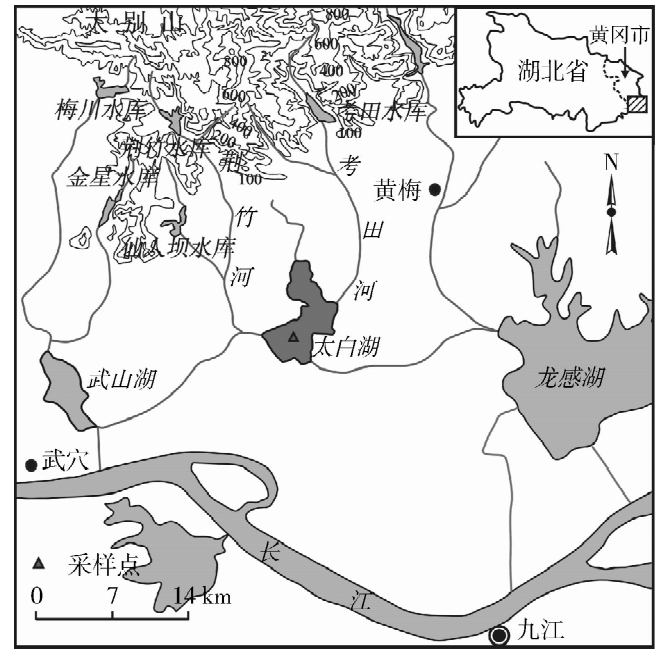

图 1 太白湖流域略图及采样点位置

Fig. 1 Sketch map of Lake Taibai

Catchment and core site

\section{1 研究区自然概况及人类活动特征}

太白湖位于湖北省黄冈市东南部,横跨武穴、黄梅 两县, 属华阳河流域; 为亚热带季风气候, 多年平均降 水量 $1273 \mathrm{~mm}$ 、蒸发量 $1041 \mathrm{~mm}$. 太白湖流域面积 607 $\mathrm{km}^{2}$, 北部为大别山南麓伸延的丘陵地带, 南部为广阔 的长江泛滥平原. 20 世纪 30 年代前后湖泊面积约 $69.2 \mathrm{~km}^{2[6,12]}$, 根据 2002 年遥感影像解译结果, 湖泊面 积为 $28.98 \mathrm{~km}^{2}$ (图 1). 太白湖多年平均水深 3.2 $\mathrm{m}^{[6]}$, 湖水依靠地表径流和湖面降水补给, 除接纳上游 的荆竹河、考田河等来水外, 汛期还西承武山湖来水, 一般情况下湖水处于微流状态; 太白湖无直接通江河 流, 湖水大部分从南部的梅济港泄人龙感湖后排人 长江.

太白湖流域经济类型以农业为主,为改善排灌体 系,降低旱涝灾害损失,20 世纪 50 年代开始,人们对太 白湖流域水系进行了大规模的改造, 1955 年在梅济港 建成了梅济新闸, $1958-1963$ 年,相继修建了荆竹水 库、仙人坝水库、考田水库 ${ }^{[12]}$. 一系列水利工程的建设 也为湖区垦殖提供了便利条件,仅 1958 年,太白湖西南部围脣面积就达 $6.67 \mathrm{~km}^{2}$. 历经围崖, 2002 年太白 湖面积仅为 20 世纪 30 年代的 $41.87 \%$.

\section{2 材料与方法}

2004 年 2 月,利用奥地利产水上采样平台和活塞采样器,在太白湖采集了长 $1.5 \mathrm{~m}$ 的柱状沉积岩芯 (图 1). 沉积岩芯现场分样, 上部 $50 \mathrm{~cm}$ 每个样品厚度 $0.5 \mathrm{~cm}$, 下部样品厚度为 $1 \mathrm{~cm}$, 样品运回实验室后进行沉 积指标分析. ${ }^{210} \mathrm{~Pb}$ 测试采用美国 EG \& G Ortec 公司生产的高纯锗井型探测器与 Ortec919 型谱控制器和 IBM 微机构成的 $16 \mathrm{~K}$ 多道分析器所组成的 $\gamma$ 谱分析系统. 孢粉样品采用酸碱法处理,选择禾本科、松属、灌 木花粉作为主要指标, 反映流域森林的砍伐及耕作业的规模变化 ${ }^{[13]}$.

20 世纪 50 年代以来湖泊形态及面积变化资料来源如下:50 年代中期湖泊形态及面积引自《湖北省湖 泊变迁图集》(1989 年),60 年代中期湖泊形态及面积采用 1965 年绘制的 1:50000 地形图量算, 1978、2002 
年湖泊形态及面积采用遥感影像解译结果.

太白湖流域的古角、考田、白湖渡雨量站只有 1956 年以来的降水量数据, 尚不能满足本文分析的需要. 长江中下游地区均属于亚热带季风气候类型, 降水尤其是暴雨主要集中在夏季, 降水量的变化规律相似 ${ }^{[14]}$, 因此采用长江 中下游六个站点 (上海、南京、九江、武汉、长沙、宜昌) 夏季降水变率的均值来 反映太白湖流域降水量的变化.

\section{3 结果与分析}

太白湖沉积岩芯 ${ }^{210} \mathrm{~Pb}_{\mathrm{ex}}$ 波动幅度交大, 不完全呈指数分布 (图 2 ), 不适宜 用 CIC 模式计算沉积速率 ${ }^{[15,16]}$; 近百年来太白湖流域人类活动强度及降水量 变化较大, 人湖泥沙量及湖泊沉积通量可能存在较大波动, 本文采用 CRS 模 式对太白湖 ${ }^{210} \mathrm{~Pb}$ 数据进行计算 ${ }^{[15,16]}$, 得到的沉积岩芯年代、深度及沉积通量 的对应关系如图 3 所示. 沉积岩芯表层年代为 $2002 \pm 1$ 年, $39.5 \mathrm{~cm}$ 处对应的 年代为 $1839 \pm 16$ 年, 每个子样品的年分辨率为 $1-9$ 年不等. 1900 年之前, 沉 积通量也存在波动, 但由于测年样品间隔较大, 每个测年样品代表的年龄较 长, 反映的沉积通量变化精度较低, 本文只对 1900 年以来沉积通量的变化规 律进行分析. 从图 3 可以看出, 近百年来太白湖存在 6 个沉积通量较高的时 段, 分别为 $1900-1920 、 1928 、 1937-1942 、 1953-1954 、 1958-1970 、 1983-$ 1993 年; 除此之外, 近 50 年来,沉积通量相对偏低.

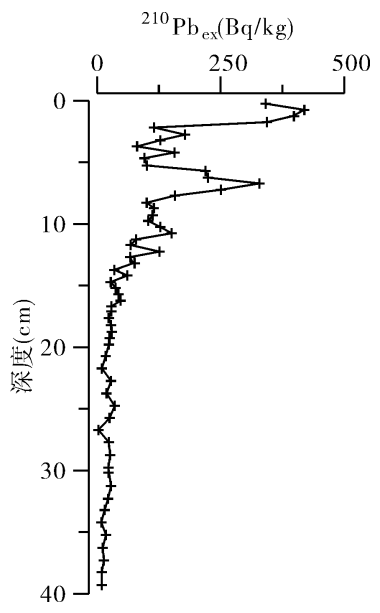

图 2 沉积岩芯中 ${ }^{210} \mathrm{~Pb}_{\text {ex }}$ 活度随深度的变化 Fig. $2{ }^{210} \mathrm{~Pb}_{\text {ex }}$ activity versus depth in the sediment core

20 世纪 50 年代中期太白湖湖泊面积 $63.70 \mathrm{~km}^{2}$, 水面面积 $60.10 \mathrm{~km}^{2}$,与 30 年代相比,湖泊面积仅减少 了 $5.5 \mathrm{~km}^{2}$, 年均减少 $0.2 \mathrm{~km}^{2}$;50 年代中期至 60 年代中期, 由于湖泊围垦, 湖泊面积 (水面面积) 减少至 $40.01 \mathrm{~km}^{2}, 10$ 年内湖泊水面面积减小了 $33.4 \%$, 年均减少 $2.0 \mathrm{~km}^{2}$; 至 1978 年, 太白湖水面面积仅为 27.02 $\mathrm{km}^{2}$, 比 60 年代中期减小了 $32.5 \%$, 年均减少 $1.08 \mathrm{~km}^{2}$. 近年来由于退耕还湖等政策的实施,太白湖湖泊面 积略有增加,2002 年水面面积为 $28.98 \mathrm{~km}^{2}$ (图 4). 从近 70 年来太白湖面积的变化可以看出,50 年代中期 以前, 湖泊围垦面积较小; 大规模的湖泊围圼主要是 50 年代中期至 1978 年之前的这段时期, 其中以 50 年 代末期至 60 年代初期湖泊围脣规模最大;70 年代末期以来湖泊围脣基本停止.

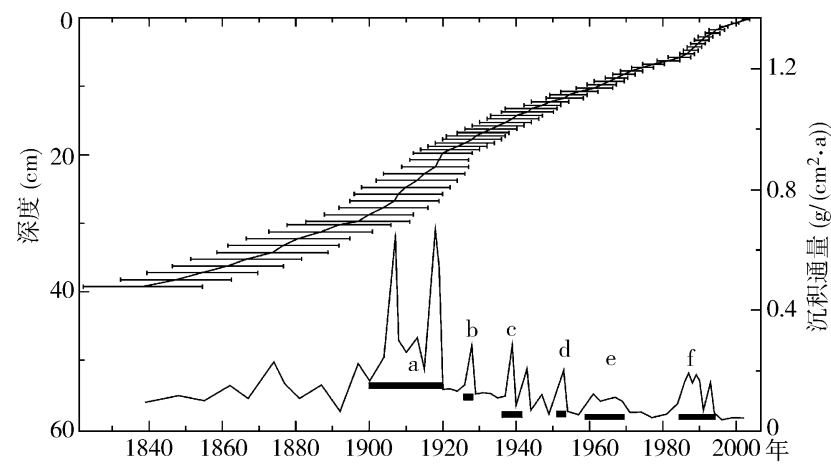

图 3 沉积通量变化及深度 - 年代对应结果

Fig. 3 Sedimentary flux and age-depth curve

湖泊沉积物中孢粉组合特征指示了流域植被类型的演化 ${ }^{[13]}$. 太白湖沉积物中木本植物花粉以松属为 主, 占到花粉总含量的 $60 \%$ 左右; 草本植物花粉以禾本科为主, 其含量为 $14 \%$; 灌木花粉含量约占 $4 \%$. 从 近 50 年来孢粉组合变化特征可以看出,60 年代禾本科花粉含量较高,松属花粉含量降低, 反映了太白湖流 

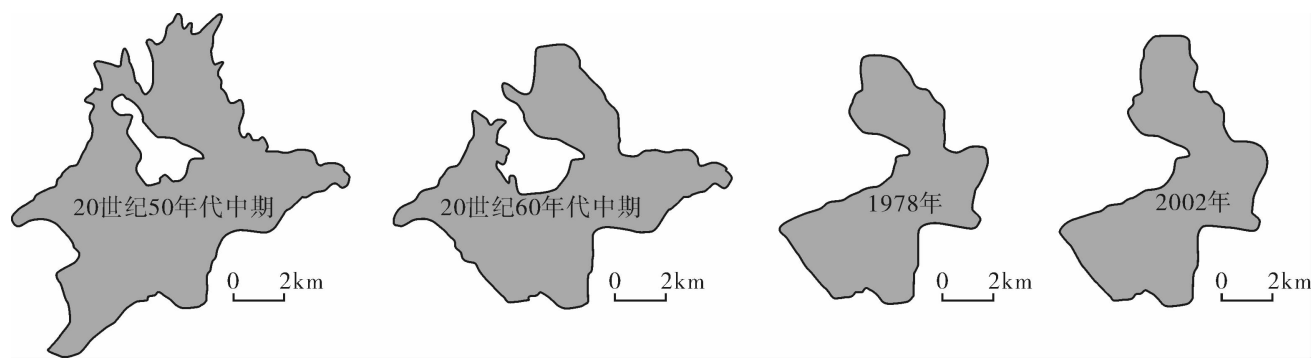

图 4 太白湖面积及形态变化

Fig. 4 Surface area and shape of Lake Taibai in history
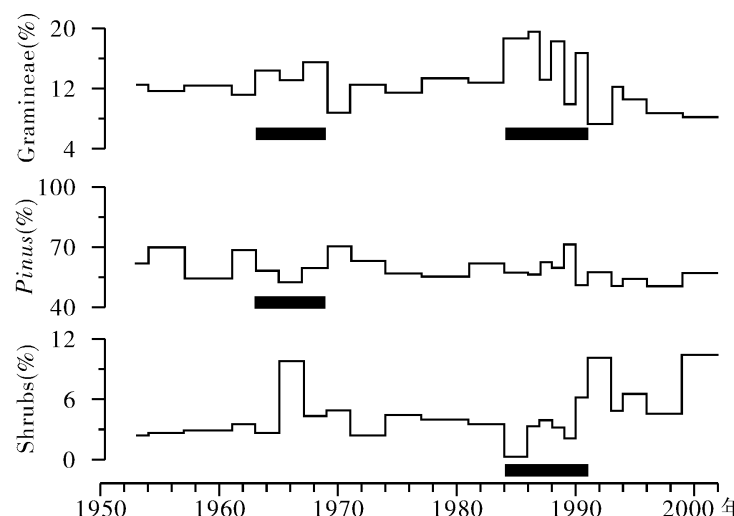

图 5 太白湖沉积岩芯中孢粉组合特征

Fig. 5 Pollen percentage in the core sediments of Lake Taibai

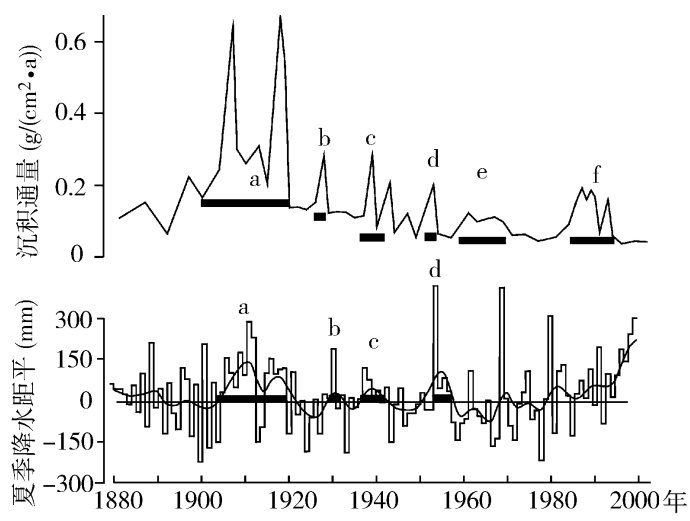

图 6 太白湖沉积沉积通量变化及长江中下游 地区夏季降水变率 (下图引自 Gong et $a l^{[14]}$ )

Fig. 6 Sedimentary flux of Lake Taibai and annual anomalies of summer precipitation in the middle and lower reaches of the Yangtze River (lower figure from Gong et $a l^{[14]}$ )
域耕作业规模的扩大及流域上游地区森林的砍伐; 80 年代中期至 90 年代初期,禾本科花粉含量出现 第二个峰值, 灌木花粉含量降低, 这一阶段沉积物 孢粉组合指示了农业实行联产承包制之后,太白湖 流域耕作业的快速发展及低海拔地区植被覆盖度 的降低;90 年代中期以来,禾本科花粉含量降低,灌 木花粉含量升高, 指示了流域植被覆盖度的逐渐恢 复 (图 5).

近百年来夏季降水偏多的年份主要是 1900 $1920 、 1931 、 1938-1939 、 1954 、 1969 、 1974-1975$ 年, 80 年代以来夏季降水量总体偏多 ${ }^{[14]}$ (图 6).

\section{4 讨论}

近百年来, 太白湖无直接通江河流, 湖水流人 龙感湖后排人长江, 这两个湖泊平均水位差近 1 $\mathrm{m}^{[6]}$; 龙感湖原有面积 $578.95 \mathrm{~km}^{2}$, 围垦后现有面积 $316.2 \mathrm{~km}^{2[17]}$, 分别为太白湖围垦前、后面积的 8.4 、 10.9 倍. 由于龙感湖的调蓄作用, 江水倒灌或顶托 作用对太白湖沉积环境的影响较弱,因此,太白湖沉 积通量变化主要受流域人湖泥沙量及湖面面积的 控制.

在人类活动影响较弱的时期, 湖泊沉积通量主 要与人湖泥沙量及降水量 (地表径流强度) 有关. 夏 季降水变率较小的年份, 人湖泥沙来源比较稳定; 但 在夏季降水量偏多 (洪涝) 的年份, 流域侵蚀强度增 加, 较多的泥沙被带人湖泊, 即使出湖泥沙量也增 加, 湖泊中泥沙沉积量仍会比常年偏高. 当流域水 系格局受到人为改造后, 上述湖泊沉积通量与降水 量的关系可能发生变化. 比如, 湖泊面积减小, 即使 人湖、出湖泥沙量不发生大的改变, 湖泊沉积通量也 会增加; 另一方面, 人湖河流上游地区水库等水利设 施的修建, 对洪水起到一定的调蓄作用, 对泥沙也有 拦截作用,能降低原有的人湖泥沙量. 
从太白湖沉积通量来看, $1900-1920 、 1928 、 1937-1942 、 1953-1954$ 年四个时期沉积通量较高, 而 1900 - 1920、1931、1938-1939、1954 年四个时段夏季降水偏多(图 6) ,二者所反映的年代误差在 4 年之内,鉴 于 ${ }^{210} \mathrm{~Pb}$ 测年结果误差, 上述沉积通量较高的四个时期分别可与夏季降水偏多的四个时段对应. 从较高沉积 通量持续时间来看, 1928、1937-1942 和 1953-1954 年三个沉积通量较高的时段持续较短,而且沉积通量 存在明显的峰值. 20 世纪 50 年代中期之前, 太白湖水系格局基本上为自然状态 ${ }^{[12]}$, 流域人为活动强度 (农 业规模) 相对较弱, 因此,这三个时段较高的沉积通量主要是夏季降水量增加, 流域侵蚀强度增加,较多的 泥沙被带人湖泊中沉积所致. $1900-1920$ 年持续较高的沉积通量与降水量偏多一致; 而且 20 世纪初期,太 白湖流域农业规模、人为活动强度等都无明显的增加,较高的沉积通量也主要与较强地表径流带人湖泊的 泥沙量增加有关.

$1958-1970$ 年沉积通量持续较高,而这一时段降水量总体相对偏少; 即使在降水量较多的年份 (1969 年) ${ }^{[18,19]}$, 沉积通量也未表现出峰值. $1958-1970$ 年正好是新中国成立后人口急剧增加、农业快速发展的 时期,这一时段沉积物中较高的禾本科花粉含量也指示了农业规模的扩大; 这一时期湖泊围怎加剧, 相继建 立了万丈湖、丰收围、连结围等农场, 50 年代中期至 1978 年,太白湖水面面积减小了 $33.08 \mathrm{~km}^{2}$,减少 $55 \%$. 一方面由于湖泊围剭, 较多的泥沙被带人湖泊, 另一方面, 围怎后湖泊面积减小, 单位面积泥沙量相对增加. 吴艳宏等对龙感湖研究结果也表明,50 年代末期 - 60 年代的湖泊围层也导致了湖泊沉积通量的显著增 加 ${ }^{[17]}$. 因此, 1958-1970 年太白湖较高的沉积通量主要是由湖泊围怎所导致的.

1958 - 1963 年,太白湖上游的仙人坝水库、考田水库、荆竹水库等相继建成后, 对夏季降水量及人湖泥 沙量起到很大的调蓄作用, 即使 $1969 、 70$ 年代中期、80 年代初期降水相对偏多的时段 ${ }^{[18,19]}$, 沉积通量也无 明显的增加,因此,太白湖沉积通量的变化受流域降水量影响程度已明显减弱.

$1983-1993$ 年沉积通量较高, 与此同时这一时段的降水量也较多,但 60 年代中期之后,太白湖上游水 库的调蓄作用使得沉积通量与降水量的关系已经较弱,1983-1993 年沉积通量较高可能是与人类活动有 关. 虽然 20 世纪 80 年代是湖北省围湖造田发展较快的时期,但 70 年代末期以来,太白湖湖泊面积并无大 的变化,基本维持在 $27-29 \mathrm{~km}^{2}$ 上下. 由此得出,1983-1993 年太白湖沉积通量的增加并不是由于湖泊围 脣造成的,与 $1958-1970$ 年湖泊沉积通量增加的原因并不相同. 从孢粉含量变化不难看出,80 年代中期 90 年代初期, 禾本科花粉含量较高, 指示了耕作业规模的扩大; 灌木花粉含量降低指示了低海拔地区植被 覆盖度的降低. 这一阶段也是改革开放农业发展最快的时期, 由原来的集体农业转变为以家庭为主体的农 业生产方式,农业生产方式的转变也导致了水土流失等一系列的问题 ${ }^{[20]}$. 因此, $1983-1993$ 年太白湖较高 的沉积通量可能与农业发展导致的水土流失加重有关.

近 50 年来,除了沉积通量较高的时段之外,太白湖沉积通量与 50 年代之前相比偏低,这与龙感湖近百 年来沉积通量变化正好相反 ${ }^{[17]}$; 这是由于太白湖流域面积较小,物质来源较单一, 60 年代初期太白湖上游 地区三座水库修建后对泥沙的拦截作用使人湖泥沙量减少,沉积通量降低.

近百年来太白湖沉积通量变化的主导因素阶段性特征明显,与流域降水量及湖泊围剭、水库建设、耕作 业发展规模等变化阶段具有较好的一致性, 表明湖泊沉积记录能够较好的反映流域气候 (降水) 及人类活 动变化, 验证了太白湖沉积岩芯年代标尺的精确性; 同时也说明太白湖沉积环境较稳定、沉积物连续性好, 沉积物受到风浪或人为扰动作用较弱,可采用太白湖沉积指标进行流域及湖泊环境演化重建.

\section{5 结论}

本次研究所钻取的太白湖沉积岩芯上部 $0-40 \mathrm{~cm}$ 为近 160 年来的沉积,沉积通量变化与流域降水量、 湖泊围垦等人类活动阶段吻合. 20 世纪 50 年代以前, 沉积通量主要受流域夏季降水量的影响, $1900-$ $1920 、 1931 、 1938-1939 、 1954$ 年四个夏季降水偏多的时段在湖泊沉积中有较好的体现,沉积通量较高. 20 世纪 50 年代末期以来, 由于太白湖上游水库建成后的调蓄作用,湖泊沉积通量变化受流域降水量变化的影 响已较弱,主要与湖泊围剭、耕作业规模变化等人类活动有关. $1958-1970$ 年较高的湖泊沉积通量反映了 太白湖围剭阶段. 而 $1983-1993$ 年较高的沉积通量则指示了农业生产方式的改变与农业规模扩大所导致 的水土流失的加重. 上游水库的调蓄作用,使得近 50 年来太白湖沉积通量相对偏低. 太白湖沉积岩芯沉积 
通量变化阶段与流域降水量、人类活动变化阶段一致,说明采用 ${ }^{210} \mathrm{~Pb}$ 强度及 CRS 模式所建立的沉积岩芯年 代标尺精度较高, 太白湖沉积环境稳定, 可采用太白湖沉积指标进行流域及湖泊环境演化重建的进一步 研究.

致谢: 吴艳宏研究员、潘红焦高级工程师、姚书春博士等协助野外采样, 吴瑞金研究员与吴艳宏研究员对论 文的写作提出了宝贵意见,在此表示感谢!

\section{6 参考文献}

[1] 黄成彦. 䝠和园昆明湖 3500 余年沉积物研究. 北京: 海洋出版社, 1996.

[2] 杨达源, 王云飞. 近 2000 年淮河流域地理环境的变化与洪灾一一黄河中游的洪灾与洪泽湖的变化. 湖泊科学, 1995, 7(1): 1-7.

[3] 羊向东, 王苏民, 沈 吉等. 近 $0.3 \mathrm{ka}$ 来龙感湖流域人类活动的湖泊环境响应. 中国科学 ( D 辑), $2001,31(12): 1031-1038$.

[4] 张佳华, 孔昭宸, 杜乃秋. 北京房山东甘池 15000 年以来碳屑分析及对火发生可能性的探讨. 植物 生态学报, 1997, 21(2): 161-168.

[5] 张振克, 王苏民, 沈吉等. 黄河下游南四湖地区黄河河道变迁的湖泊沉积记录. 湖泊科学, 1999, 11(3): $231-236$.

[6] 王苏民, 窦鸿身. 中国湖泊志. 北京: 科学出版社, 1998.

[7] Du Y, Cai S M, Zhang X Y et al. Interpretation of the environmental change of Dongting Lake, middle reach of Yangtze River, China, by ${ }^{210} \mathrm{~Pb}$ measurement and satellite image analysis. Geomorphology, 2001, 41 : $171-181$.

[8] Xiang L, Lu X X, Higgitt D L et al. Recent lake sedimentation in the middle and lower Yangtze basin inferred from ${ }^{137} \mathrm{Cs}$ and ${ }^{210} \mathrm{~Pb}$ measurements. Journal of Asian Earth Sciences, 2002, 21 : 77 - 86 .

[9] 崔宁宁. 近百年来巢湖沉积物重金属元素分布规律探究. 南京大学硕士学位论文, 2006.

[10] Geiss C E, Banerjee S K, Camill P et al. Sediment-magnetic signature of land-use and drought as recorded in lake sediment from south-central Minnesota, USA. Quatern Res, 2004, 62 : 117 - 125.

[11] Jordan G, Van Rompaey A, Szilassi P et al. Historical land use changes and their impact on sediment fluxes in the Balaton basin (Hungary). Agric, Ecosyst Environ, 2005, 108:119-133.

[12] 黄冈地区水利志编纂委员会、湖北省黄冈市水利局. 黄冈地区水利志. 北京: 中国水利水电出版 社, 1997.

[13] Huang C C, Connell M O. Recent land-use and soil-erosion history within a small catchment in Connemara, western Ireland: evidence from lake sediments and documentary sources. Catena, 2000, 41: 293 - 335.

[14] Gong D Y, Zhu J H, Wang S W. Flooding 1990s along the Yangtze River, has it concern of global warming? Journal of Geographical Science, 2001, 11(1): $43-44$.

[15] Appleby P G, Oldfield F. The calculation of ${ }^{210} \mathrm{~Pb}$ dates assuming a constant rate of supply of unsupported ${ }^{210} \mathrm{~Pb}$ to the sediment. Catena, 1978, 5: $1-8$.

[16] William M L, John P S. Tracking environmental change using lake sediment, Volume 1: basin analysis, coring, and chronological techniques. Kluwer Academic Publishers, 2004:186 - 188 .

[17] 吴艳宏, 王苏民, 夏威岗等. 近代湖泊沉积物球状碳颗粒 (SCP) 定年. 科学通报, 2005, 50(7): 703 -707 .

[18］张 强. 1969 年长江中下游暴雨特征及灾情分析. 灾害学, 1996,11(1): 38 - 42 .

[19] 陈菊英. 长江中、下游特大暴雨洪水的成功预报和科学依据. 地学前缘, 2001, 8 (1): 113-121.

[20] 刘湘南, 黄 方. 土地利用变化驱动下的区域生态环境退化机制分析. 东北师大学报 (自然科学版), $2002, \mathbf{3 4}(1): 87-92$. 